\title{
Extracorporeal life support in patients with severe trauma: An advanced treatment strategy for refractory clinical settings
}

\author{
Massimo Bonacchi, MD, ${ }^{\mathrm{a}}$ Rosario Spina, MD, ${ }^{\mathrm{b}}$ Leonardo Torracchi, MD, ${ }^{\mathrm{a}}$ Guy Harmelin, MD, ${ }^{\mathrm{a}}$ \\ Guido Sani, MD, ${ }^{a}$ and Adriano Peris, $\mathrm{MD}^{\mathrm{b}}$
}

\begin{abstract}
Objectives: Major trauma is a leading cause of death, particularly among young patients. New strategies in management are needed to improve poor outcomes in cases of severe trauma. Extracorporeal life support (ECLS) has proven to be effective in acute cardiopulmonary failure of different causes, even when conventional therapies fail. We report our initial experience with ECLS as a rescue therapy in severely polytraumatized patients in a refractory clinical setting. This study identifies the pre-ECLS characteristics of patients to predict the appropriateness of ECLS treatment.
\end{abstract}

\begin{abstract}
Methods: From December 2008 to May 2012, 375 patients with polytrauma were treated in the Careggi Teaching Hospital, a tertiary-level referral trauma center. Our ECLS team was alerted on 30 patients and applied ECLS in 18 adult patients with trauma. We adopted venoarterial ECLS in 14 patients with cardiopulmonary failure with refractory shock and venovenous ECLS in 4 patients with isolated refractory acute respiratory failure.
\end{abstract}

Results: ECLS was initiated at a mean of $359.176 \pm 216.606$ (145-950) minutes from trauma. In 4 patients, the ECLS treatment failed because of an incapability to maintain adequate ECLS flow and perfusion. In 14 patients, efficiently supported by ECLS, the cardiac index, mean arterial pressure, blood lactate concentration, arterial oxygen tension, arterial carbon dioxide tension, and $\mathrm{pH}$ showed significant improvement, with normal values reached at $3.5 \pm 1.5$ hours.

Conclusions: From our data, ECLS seems to be a valuable option to resuscitate patients with severe trauma when conventional therapies are insufficient. ECLS is safe, feasible, and effective in providing hemodynamic support and blood gas exchange. (J Thorac Cardiovasc Surg 2013;145:1617-26)

Major trauma is a leading cause of death, particularly among young patients, occurring in more than 5 million persons worldwide each year. ${ }^{1}$ Death by trauma can occur in 3 ways. Immediate death (on stage) is caused by untreatable injuries, such as aortic rupture or cervical spinal lesions. Early causes of death (hours to a few days) are severe and usually related to severe hemorrhage, pulmonary failure, cardiovascular shock, or extensive brain injury. Late deaths (days to weeks) are usually due to secondary infections or multiple organ failure. Early causes of death are the most important in determining the poor outcome of severe trauma; a dramatic decline in survival has been noted in the first 10 days of hospital stay. $^{2}$

\footnotetext{
From the Medical and Surgical Critical Care Department, ${ }^{\text {a }}$ Cardiac Surgery, University of Florence; and Emergency Department, ${ }^{\mathrm{b}}$ Anesthesia and Intensive Care Unit, Careggi Teaching Hospital, Florence, Italy.

Disclosures: Authors have nothing to disclose with regard to commercial support.

Received for publication June 5, 2012; revisions received July 19, 2012; accepted for publication Aug 20, 2012; available ahead of print Sept 17, 2012.

Address for reprints: Massimo Bonacchi, MD, Cardiac Surgery, Medical and Surgical Critical Care Department, Careggi Teaching Hospital, Largo Brambilla, 3, 50134, Firenze, Italy (E-mail: massimo.bonacchi@unifi.it).

$0022-5223 / \$ 36.00$

Copyright (c) 2013 by The American Association for Thoracic Surgery

http://dx.doi.org/10.1016/j.jtcvs.2012.08.046
}

Conventional therapies for post-traumatic cardiovascular shock and acute pulmonary failure may be insufficient and even dangerous. Massive blood transfusions, even if effective in restoring blood volume, may have a disastrous effect on blood coagulation, acid-base balance, and lung (transfusion-related acute lung injury) and organ perfusion. $^{3-5}$ Aggressive mechanical ventilation strategies in case of refractory pulmonary failure can worsen lung function by inducing ventilator-induced lung injury. ${ }^{6-8}$ High doses of vasoconstrictor/inotropic drugs may have a disastrous effect on the heart and microcirculation, inducing severe heart dysfunction, myocardial stunning, and worsening organ perfusion. ${ }^{1,4,5,9,10}$ All of these physiopathologic effects due to conventional treatment may create an unavoidable and potentially lethal vicious circle.

New approaches in trauma care and advanced treatments are needed to modify the actual therapeutic strategy and treatment protocols. Extracorporeal life support (ECLS) has proven to be effective in shock status and pulmonary failure, even when standard therapies have failed. ${ }^{9-11}$ ECLS can provide full hemodynamic support (in venoarterial [VA] configuration) in cases of refractory shock unresponsive to conventional treatment, allowing time for diagnosis and heart recovery. Moreover, even in 


$$
\begin{aligned}
& \text { Abbreviations and Acronyms } \\
& \mathrm{BL}=\text { blood lactate } \\
& \mathrm{CA}=\text { cardiac arrest } \\
& \mathrm{CI}=\text { confidence interval } \\
& \text { ECLS }=\text { extracorporeal life support } \\
& \text { IS = inotropic score } \\
& \text { ISS = injury severity score } \\
& \mathrm{OR}=\text { odds ratio } \\
& \mathrm{PaO}_{2}=\text { arterial oxygen tension } \\
& \text { ROC }=\text { receiver operating characteristic } \\
& \mathrm{VA}=\text { venoarterial } \\
& \mathrm{VV}=\text { venovenous }
\end{aligned}
$$

cases of refractory pulmonary failure, complete gas exchange is ensured by ECLS (in venovenous [VV] configuration), improving blood oxygenation and carbon dioxide removal, allowing time for lung recovery, and reducing mechanical ventilation invasiveness.

Nevertheless, the need for anticoagulation to prevent clot formation in the circuit has not allowed the widespread use of ECLS in patients with polytrauma until recently, mostly because of multiple injuries and increased risk of bleeding. Since the first use of ECLS in a patient with trauma, performed by Donald Hill in 1972, ${ }^{12}$ many changes and improvements in devices and materials biocompatibility have made the deployment of ECLS safer and easier even in complex and polytraumatized patients. ${ }^{9-11,13}$ Heparin-coated circuits decrease blood coagulation activation and allow starting heparin-free ECLS, delaying heparin administration for just 48/72 hours. ${ }^{5,13}$ Percutaneous cannulation and double-lumen catheters (for VV-ECLS) enable less-invasive and faster procedures that are suitable for emergency situations. Oxygenators and centrifugal pumps have become more compatible with blood, reducing hemolysis and platelet consumption, and the need for blood component transfusions. In adjunct, as suggest by Larsson and colleagues,${ }^{13}$ there is a possible favorable role for VA-ECLS in controlling venous hemorrhage by reducing central venous pressure with active drainage from this area.

We report our initial experience in initiating ECLS as a rescue therapy in patients with severe trauma in a severe clinical setting (cardiogenic shock, cardiac arrest [CA], or pulmonary failure) who have been shown to be refractory to conventional treatments. The rationale for using ECLS in patients with trauma is to treat refractory pulmonary and cardiopulmonary failure, provide adequate systemic perfusion, avoid consequent multiple organ failure, and permit organ recovery. ${ }^{5,14,15}$ Furthermore, we have identified several polytraumatized patient characteristics as predictors of the appropriateness of ECLS treatment. In addition, ECLS in select polytraumatized patients may be used to support vital functions, allowing time for adequate brain assessment. ${ }^{16,17}$

\section{MATERIALS AND METHODS}

An ECLS program has been used since 2006 in the Careggi Teaching Hospital (Florence, Italy) with collaboration between the emergency department and the heart and vessel department. Our ECLS team, composed of a cardiac surgeon, an anesthesiologist, a cardiologist, and a perfusionist, provides 24-hour coverage for emergencies with a fully deployed reaction time of 20 minutes. The team ensures both indoor and out-of-center ECLS deployment, with a dedicated and fully equipped ambulance. ${ }^{18}$ Generally speaking, because of the invasiveness and high hemorrhagic risk, ECLS is started when the team is convinced that standard therapies have been exhausted and no improvement is anticipated, but the patient's injuries are considered to be potentially reversible with adequate life support.

From December 2008 to May 2012, 375 polytraumatized patients were treated in our hospital, and our ECLS team was alerted for $30(8 \%)$ of these. In 12 patients, ECLS was not started because of massive and intractable bleeding (skeletal, retroperitoneal, aortic lesions, $\mathrm{n}=8$ ), certain prolonged hypoxemia $(\mathrm{n}=2)$, and advanced age $(>75$ years, $\mathrm{n}=2)$. The other 18 adult patients with trauma (mean age, $46.3 \pm 17.6$ years [range, 15-69 years]; mean injury severity score [ISS], $53 \pm 17$ [range, 18-75]) underwent ECLS for refractory cardiopulmonary failure. Data of polytraumatized patients who received ECLS support were prospectively collected in our database (Table 1). Depending on the patient's clinical condition, mainly worsening of cardiocirculatory and pulmonary function, we initiated ECLS in the emergency department $(n=6)$ or operating room $(n=2)$ during damage control surgery, or in the intensive care unit $(\mathrm{n}=10)$ (Figure 1).

\section{Initiating Extracorporeal Life Support}

ECLS was initiated after a fast clinical and instrumental reevaluation performed by ECLS team members, collegially with emergency department staff. ECLS contraindications were judged as follows: advanced age ( $>65 / 70$ years), witnessed prolonged hypoxemia (eg, prolonged inefficacious resuscitation in trauma department), potentially fatal preexisting disease, and incontrollable major bleeding (eg, aortic rupture). When possible (in 12 patients, $66.7 \%$ of total), we performed a total-body computed tomography scan before deciding to perform ECLS. The idea behind this was to identify complete injury patterns and eventually the presence of hidden absolute contraindications.

The indication for VA-ECLS ( $\mathrm{n}=14$ patients, $77.8 \%$ ) was cardiopulmonary failure with shock $(\mathrm{n}=3,16.7 \%)$ or post-traumatic CA $(\mathrm{n}=11$ patients, $61.1 \%$ ) that was refractory to conventional resuscitative treatment. VV-ECLS ( $\mathrm{n}=4$ patients, $22.2 \%$ ) was indicated instead in patients with post-traumatic respiratory insufficiency with severe hypoxemia (arterial oxygen tension $\left[\mathrm{PaO}_{2}\right] /$ inspired oxygen fraction ratio $<100$ ) or hypercapnic acidosis that was refractory to advanced mechanical ventilation management (Table 1). In all cases, a percutaneous cannulation procedure was carried out by using the Seldinger technique without any skin incision, thus preventing future cannula site bleeding. Transthoracic/transesophageal ultrasonography was performed to guide and evaluate the position and definitive setting of the cannulas.

In VA-ECLS cases, we adopted the femoro-femoral configuration; to prevent leg ischemia, a small shunt cannula $(8 \mathrm{~F}-10 \mathrm{~F})$ was inserted in the femoral artery distal to the ECLS cannula. In VV-ECLS, we used 2 cannulas in a femoro-jugular setting $(\mathrm{n}=2)$ or a single bilumen cannula (and only 1 jugular access, $\mathrm{n}=2$ ). In case of VV-ECLS in a femoro-jugular setting, we used a previously reported original technique, the $\chi$-configuration, to optimize extracorporeal blood oxygenation. ${ }^{19}$ In all cases, because of actual or potential bleeding risk, we initially performed heparin-free ECLS until bleeding stopped and normalization of patient coagulative status was achieved (Table 2). 
TABLE 1. Patient characteristics and outcome

\begin{tabular}{|c|c|c|c|c|c|c|c|c|c|}
\hline Patient & $\begin{array}{c}\text { Age, } \\
\mathbf{y}\end{array}$ & Gender & ECLS indication & $\begin{array}{l}\text { ACLS before } \\
\operatorname{ECLS}(\min )\end{array}$ & ISS & $\begin{array}{c}\text { ECLS } \\
\text { type }\end{array}$ & $\begin{array}{l}\text { ECLS success } \\
\text { or failure } \\
\end{array}$ & Type of trauma & Outcome \\
\hline 1 & 65 & M & $\begin{array}{l}\text { Pulmonary contusion/pulmonary } \\
\text { failure }\end{array}$ & 0 & 41 & VV & Success & Blunt (car accident) & Survived \\
\hline 2 & 37 & M & $\begin{array}{l}\text { Pulmonary contusion/pulmonary } \\
\text { failure }\end{array}$ & 0 & 75 & VV & Success & Blunt (motorcycle accident) & Survived \\
\hline 3 & 54 & M & $\begin{array}{l}\text { Pulmonary contusion/pulmonary } \\
\text { failure }\end{array}$ & 0 & 54 & VV & Success & Blunt (car accident) & Deceased \\
\hline 4 & 55 & $\mathrm{~F}$ & $\begin{array}{l}\text { Pulmonary contusion/bleeding } \\
\text { shock/CA }\end{array}$ & 100 & 66 & VA & Success & Blunt (car-pedestrian accident) & Organ donation \\
\hline 5 & 68 & M & Bleeding shock/CA & 80 & 38 & VA & Success & Blunt (car accident) & Organ donation \\
\hline 6 & 15 & M & Bleeding shock/CA & 100 & 75 & VA & Failure & Blunt (motorcycle accident) & Deceased \\
\hline 7 & 46 & M & Bleeding shock/CA & 75 & 18 & VA & Success & Blunt (accidental fall) & Organ donation \\
\hline 8 & 60 & $\mathrm{~F}$ & Bleeding shock/CA & 80 & 66 & VA & Failure & Blunt (car-pedestrian accident) & Deceased \\
\hline 9 & 46 & $\mathrm{~F}$ & Bleeding shock/CA & 90 & 67 & VA & Failure & Blunt (car accident) & Deceased \\
\hline 10 & 30 & M & Bleeding shock/CA & 60 & 41 & VA & Success & Blunt (motorcycle accident) & Survived \\
\hline 11 & 16 & M & Bleeding shock/CA & 30 & 38 & VA & Success & Blunt (motorcycle accident) & Survived \\
\hline 12 & 67 & $\mathrm{~F}$ & $\begin{array}{l}\text { Pulmonary contusion/bleeding } \\
\text { shock/CA }\end{array}$ & 30 & 54 & VA & Success & Blunt (car-pedestrian accident) & Organ donation \\
\hline 13 & 54 & M & Bleeding shock & 0 & 66 & VA & Success & Blunt (motorcycle accident) & Deceased \\
\hline 14 & 40 & M & $\begin{array}{l}\text { Pulmonary contusion/pulmonary } \\
\text { failure }\end{array}$ & 0 & 18 & VV & Success & Blunt (crash) & Survived \\
\hline 15 & 19 & $\mathrm{~F}$ & $\begin{array}{l}\text { Pulmonary contusion/pulmonary } \\
\text { failure }\end{array}$ & 0 & 66 & VA & Success & Blunt (car accident) & Organ donation \\
\hline 16 & 69 & $\mathrm{~F}$ & Bleeding shock & 0 & 64 & VA & Success & Blunt (car-pedestrian accident) & Organ donation \\
\hline 17 & 40 & M & Bleeding shock/CA & 40 & 50 & VA & Success & Blunt (car accident) & Deceased \\
\hline 18 & 52 & M & Bleeding shock/CA & 80 & 52 & VA & Failure & Blunt (accidental fall) & Deceased \\
\hline
\end{tabular}

$E C L S$, Extracorporeal life support; $A C L S$, advanced cardiac life support; $I S S$, injury severity score; $C A$, cardiac arrest; $V V$, venovenous; $V A$, venoarterial.

\section{Extracorporeal Life Support Circuit}

The circuit we used consisted of a Rotaflow Maquet Centrifugal Pump (MAQUET GmbH \& Co KG, Rastatt, Germany) and a hollow fiber polymethylpentene membrane oxygenator (Quadrox-D Oxygenator, MAQUET $\mathrm{GmbH} \& \mathrm{Co} \mathrm{KG);} \mathrm{the} \mathrm{system} \mathrm{is} \mathrm{entirely} \mathrm{"tip-to-tip"} \mathrm{heparin} \mathrm{coated.} \mathrm{The}$ circuit includes a special intake stopcock for large-volume administration, particularly effective in polytraumatized patients who require high-speed fluid resuscitation.

Since November 2010, we have improved our instrumentation with the CardioHelp system (MAQUET GmbH \& Co KG), which is smaller and requires minimal priming volume. We have applied it in this clinical scenario in 4 patients. Depending on the patient's biometric data, we used a $21 \mathrm{~F}$ or $23 \mathrm{~F}$ arterial cannula and a $25 \mathrm{~F}, 27 \mathrm{~F}$, or $29 \mathrm{~F}$ venous cannula (PLS femoral cannula, MAQUET GmbH \& Co KG) for VA and VV (in a doublecannulation setting) ECLS. For VV-ECLS with a single cannula, we used a $29 \mathrm{~F}$ or $31 \mathrm{~F}$ Elite bilumen cannula (Avalon Laboratories, LLC, Rancho Dominguez, Calif). A heat-exchanger device was integrated in the ECLS circuit to control the patient's temperature.

\section{Extracorporeal Life Support Management and Weaning}

Blood flow provided by ECLS should be maintained in the range of physiologic cardiac output, and gas supply to the oxygenator should be regulated to reach normal blood gas concentrations, adapting them to the patient's biometric data, to achieve normal perfusion indexes (eg, acidosis, lactate blood concentration, and mixed venous oxygen saturation) and to avoid the adverse effects of hyperoxygenation or hypocapnia.

In VA-ECLS, inotropic drug infusion was progressively decreased according to the mean arterial pressure and cardiac index. In case of massive bleeding in patients, fluid resuscitation and blood component (packed red blood cells, platelets, fresh-frozen plasma) transfusions were continued until a satisfactory blood volume was reached. Activated recombinant factor VII was administered in case of refractory hemorrhage to control bleeding. ${ }^{20}$ No clotting formation in the circuit was observed after this procedure. If cardiopulmonary resuscitation was performed before ECLS and brain injury was suspected, hypothermia was rapidly initiated and maintained for 48 hours at a temperature between $32^{\circ} \mathrm{C}$ and $34^{\circ} \mathrm{C} .{ }^{21}$ Transesophageal ultrasonography was performed every 12 hours (or if clinical evidence of patient hemodynamic conditions changed) to evaluate cardiac function and cardiac recovery.

Lung-protective ventilation was adopted, and daily thoracic ultrasonography ${ }^{22}$ was performed to evaluate pulmonary conditions and eventually pulmonary recovery. A Swan-Ganz catheter (Edwards Lifesciences, Irvine, Calif) was inserted to evaluate wedge pressure and mixed venous oxygen saturation. Heparin administration was delayed in case of bleeding, allowing time for surgical hemostasis to be performed; it was started when the absence of active bleeding was confirmed, at $16.7 \pm 19$ hours (range, 2.5-72 hours) from ECLS deployment, and titrated by bedside measurement of activated partial thromboplastin time (target value, 40-50 seconds) and activated clotting time (target value, 160-180 seconds) every 2 hours. An intra-aortic balloon pump was inserted in 2 patients with CA and profound myocardial dysfunction, thus reducing cardiac afterload and promoting myocardial recover.

During ECLS treatment, additional specific modules were added to the ECLS circuit when needed for renal (continuous VV hemofiltration, $\mathrm{n}=7$ ) and hepatic $(\mathrm{n}=2)$ function, or in case of sepsis (endotoxin removal cartridge, $\mathrm{n}=3$ ). Procedures performed during ECLS are summarized in Table 2. Patients were considered ready for weaning from VV-ECLS when the pump flow could be reduced to 1.5 to $2 \mathrm{~L} / \mathrm{min}$ and an arterial saturated oxygen level of at least $90 \%$ was maintained. Weaning from VA-ECLS was instituted with mild inotropic support, progressively 


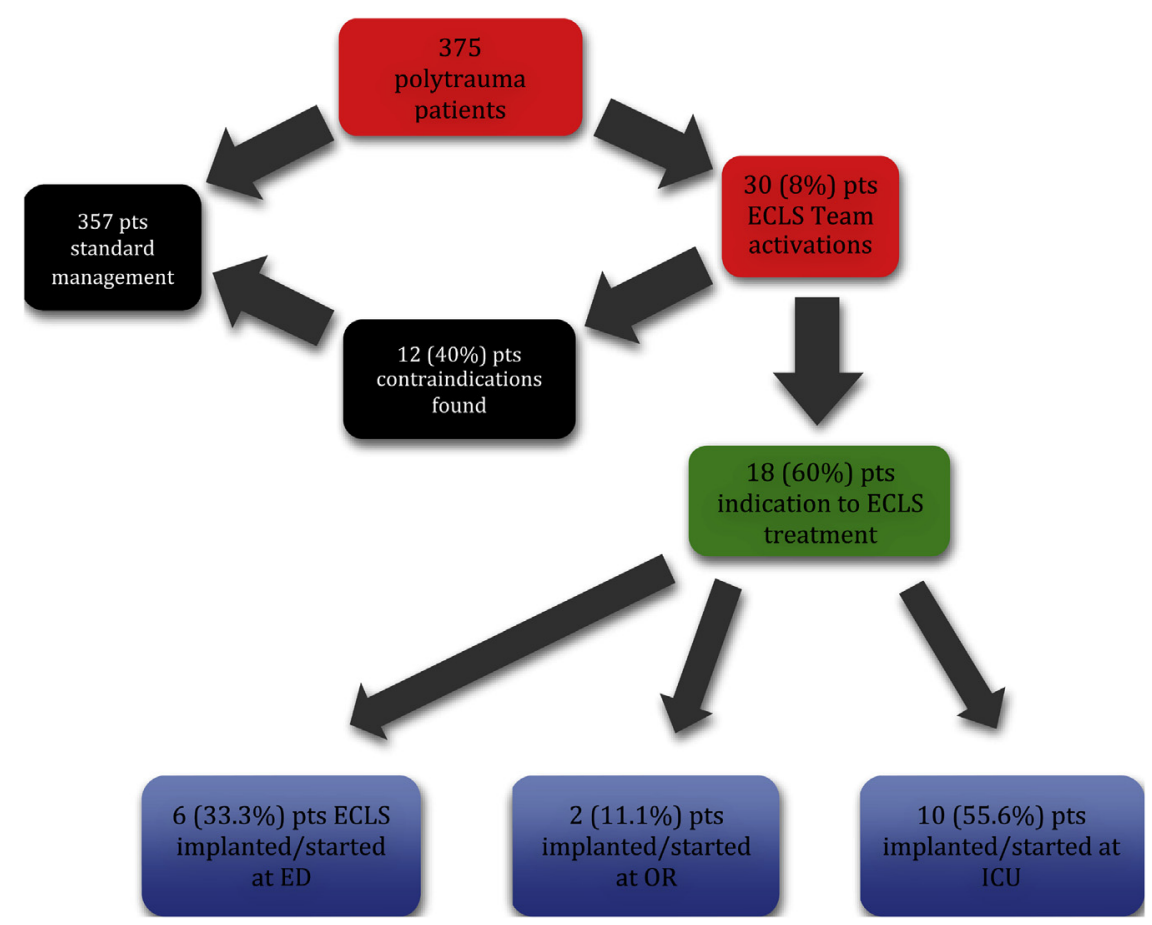

FIGURE 1. Flow-chart of management of polytraumatized patients (reported as absolute number and \%) and hospital sites of ECLS deployment. ED, Emergency department; ICU, intensive care unit; $O R$, operating room; $E C L S$, extracorporeal life support.

reducing ECLS flow and evaluating cardiac ejection fraction by transesophageal ultrasonography. If a flow of $1 \mathrm{~L} / \mathrm{min}$ could be reached with good hemodynamic stability (stable mean arterial pressure, low inotropic support request, good ejection fraction), the patient was considered ready for weaning, because cardiac function had recovered. Successful weaning was considered as weaning from ECLS followed by survival for more than 48 hours. Survival was defined as weaning from ECLS followed by discharge from the hospital.

\section{Statistical Analysis}

All statistical analyses were performed with the Statistical Package for the Social Sciences version 19.0 for Windows (SPSS Inc, Chicago, Ill). Categoric variables were expressed as percentages and evaluated with the chi-square or Fisher exact test. Continuous variables were expressed as mean \pm standard deviation (minimum and maximum values are reported in brackets) and evaluated by the Student $t$ test or Wilcoxon rank-sum test. In addition, receiver operating characteristic (ROC) curves were used to dichotomize continuous variables based on a cutoff value. Univariate and multivariate analyses were used to determine the independent predictors of unsuitability and unsuccessful ECLS treatment. Univariate analysis was conducted using the chi-square or Fisher exact test (as appropriate) for categoric data and the Student $t$ test or the Wilcoxon rank-sum test (as appropriate) for measurement data. Potential predictors with a $P$ value less than .05 on univariate analysis were included in multivariate analysis, performed using stepwise logistic regression, to identify independent predictors. In the univariate and multivariate analyses, an odds ratio (OR) and a confidence interval $(\mathrm{CI})$ with a reliability of $95.0 \%$ were obtained for all significant predictors. All $P$ values are 2 tailed.

\section{RESULTS}

Of 30 ECLS team alerts in 18 patients $(60 \%)$, ECLS was deployed according to a refractory but potentially reversible clinical setting. The ECLS device was implanted in 6 patients $(33 \%)$ in the emergency department, in 2 patients $(11 \%)$ in the operating room, and in 10 patients $(56 \%)$ in the intensive care unit, according to patients' clinical status, particularly their hemodynamic and respiratory instability (Figure 1). Twelve patients $(66.7 \%)$ underwent previous computed tomography evaluation; their demographic and clinical data are summarized in Table 1. ECLS was started

TABLE 2. Extracorporeal life support techniques, modalities, and procedures

\begin{tabular}{lc}
\hline Patient characteristics (18 patients) & Data (mean \pm SD; min-max) \\
\hline ECLS type & \\
VA & $14(78 \%)$ \\
VV & $4(22 \%)$ \\
Cannula insertion technique: & \\
Surgical & $0(0 \%)$ \\
Percutaneous & $18(100 \%)$ \\
CA before ECLS & $11(61 \%)$ \\
Heparin administration delay from ECLS & $16.7 \pm 19.5-72)$ \\
start (h) & $13(72 \%)$ \\
rfVIIa administration & \\
ECLS apply location & $6(33 \%)$ \\
Emergency department & $2(11 \%)$ \\
Operating room & $10(56 \%)$ \\
ICU &
\end{tabular}

$\overline{S D}$, Standard deviation; ECLS, extracorporeal life support; $V A$, venoarterial; $V V$, venovenous; $C A$, cardiac arrest; $r f V I I a$, recombinant factor VII activated; $I C U$, intensive care unit. 
at $359.176 \pm 216.606$ (145-950) minutes from trauma. CA was observed in 11 patients before ECLS, and in 6 of these patients CA began during advanced cardiac life support maneuvers (Table 2). No complication during the cannulation procedure was observed.

\section{Extracorporeal Life Support Success Versus Failure}

In 4 patients $(22.2 \%)$ in the ECLS failure group, ECLS treatment failed because of the inability to maintain adequate ECLS flow and patient perfusion. In this group, ECLS was stopped after a mean of $3.075 \pm 0.65$ (2.5-4) hours.

In 14 patients (77.8\%) in the ECLS success group, ECLS treatment was successful and maintained until the treatment objectives were obtained or death occurred. The differences in demographics and clinical, instrumental, and laboratory characteristics between groups were analyzed (Table 3). The baseline clinical and demographic characteristics were similar between the groups; the only differences observed were related to the pre-ECLS ISS, active bleeding time, CA duration, and inotropic score (IS). ${ }^{23,24}$ The patients with ECLS failure demonstrated significantly greater ISS ( $65 \pm 9.6$ vs $46.5 \pm 16.3, P=.0365)$, active bleeding time $(385 \pm 103.4$ minutes vs $201.4 \pm 90.9$ minutes, $P=.0032)$, CA duration (78.75 \pm 8.54 minutes vs $56.4 \pm 24.27$ minutes, $P=.0006$ ), and IS $(307.5 \pm 30.9$ vs $192.1 \pm 50.6, P=.0006)$.

The 2 groups showed no significant difference in biochemical and hematologic profiles. The only differences observed were related to the pre-ECLS $\mathrm{pH}$, blood lactate (BL) level, hemoglobin blood concentration, and blood units infused. Patients with ECLS failure demonstrated significantly higher BL level $(18.6 \pm 3 \mathrm{mmol} / \mathrm{L}$ vs $7.11 \pm 5.26$ $\mathrm{mmol} / \mathrm{L}, P=.0008)$ and blood units infused $(18.75 \pm 3.3 \mathrm{vs}$ $11.86 \pm 5.3, P=.015$ ), and significantly lower $\mathrm{pH}$ $(6.85 \pm 0.11$ vs $7.18 \pm 0.15, P=.0011)$ and hemoglobin $(5.35 \pm 0.26 \mathrm{~g} / \mathrm{dL}$ vs $5.94 \pm 0.42 \mathrm{~g} / \mathrm{dL}, P=.01)$.

In addition, for simplifying preimplantation evaluation of the patients' pre-ECLS parameters tested, ROC curves were used to dichotomize continuous variables based on a cutoff value, corresponding with the highest Youden index (Figure 2). These cutoff values were used successively to identify independent predictors of unsuitability and unsuccessful ECLS treatment with univariate and multivariate analyses. On the basis of the ROC curves, the cutoff values were greater than 63 for ISS, greater than 60 minutes for CA, less than 7.01 for $\mathrm{pH}$ (mean of last 3 evaluations), greater than $14.4 \mathrm{mmol} / \mathrm{L}$ for BL (mean of last 3 evaluations), greater than $270 \mu \mathrm{g} / \mathrm{kg} / \mathrm{min}$ for IS, greater than 22 for total blood units, less than $6.7 \mathrm{~g} / \mathrm{dL}$ for hemoglobin (mean of last 3 evaluations), and more than 200 minutes for bleeding time. These dichotomized variables and "emergency department ECLS implantation," analyzed with univariate analysis, are significant predictors associated with ECLS
TABLE 3. Comparison of pre-extracorporeal life support demographic, clinical, instrumental, and laboratory characteristics between success $(n=14)$ and failure $(n=4)$ groups with statistical evaluation results

\begin{tabular}{|c|c|c|c|}
\hline Patient characteristics & $\begin{array}{c}\text { ECLS success } \\
(14 \text { patients, } 78 \%) \\
\end{array}$ & $\begin{array}{c}\text { ECLS failure } \\
(4 \text { patients, } 22 \%) \\
\end{array}$ & $P$ \\
\hline Age (y) & $47 \pm 17.6$ & $43 \pm 19.7$ & .7085 \\
\hline Gender & $\begin{array}{l}\text { Male, } 71 \% \\
\quad \text { female, } 29 \%\end{array}$ & $\begin{array}{l}\text { Male, } 50 \% \\
\quad \text { female, } 50 \%\end{array}$ & .569 \\
\hline ISS & $46.5 \pm 16.3$ & $65 \pm 9.6$ & .0365 \\
\hline $\mathrm{CA}$ & $50 \%$ & $100 \%$ & .278 \\
\hline $\mathrm{CA}(\min )$ & $56.43 \pm 24.27$ & $78.75 \pm 8.54$ & .0006 \\
\hline ECLS insertion location & $\begin{array}{r}72 \% \text { ICU; } 14 \% \\
\text { OR; } 14 \% \text { ER }\end{array}$ & $100 \%$ ER & .0058 \\
\hline ECLS type (VA vs VV) & $\begin{array}{l}10 \text { (71\%) VA; } \\
4(29 \%) \mathrm{VV}\end{array}$ & $4(100 \%) \mathrm{VA}$ & .5959 \\
\hline $\begin{array}{l}\text { Heparin-free time } \\
\text { on ECLS (h) }\end{array}$ & $20.71 \pm 19.8$ & $2.5 \pm 1.3$ & .0905 \\
\hline IABP & $11 \%$ & $0 \%$ & .9202 \\
\hline $\mathrm{pH}$ & $7.18 \pm 0.15$ & $6.85 \pm 0.11$ & .0011 \\
\hline $\mathrm{PaO}_{2} / \mathrm{FIO}_{2}$ before ECLS & $150.4 \pm 95.1$ & $177.5 \pm 55$ & .598 \\
\hline $\begin{array}{l}\mathrm{PaCO}_{2} \text { before ECLS } \\
(\mathrm{mm} \mathrm{Hg})\end{array}$ & $52.95 \pm 8.8$ & $62.5 \pm 7$ & .0666 \\
\hline $\begin{array}{l}\text { BL concentration } \\
(\mathrm{mmol} / \mathrm{L})\end{array}$ & $7.11 \pm 5.26$ & $18.6 \pm 3$ & .0008 \\
\hline IS $(\mu \mathrm{g} / \mathrm{kg} / \mathrm{min})$ & $192.1 \pm 50.6$ & $307.5 \pm 30.9$ & .0006 \\
\hline Active bleeding & $80 \%$ & $100 \%$ & .7998 \\
\hline Blood units infused & $11.86 \pm 5.3$ & $18.75 \pm 3.3$ & .015 \\
\hline Hemoglobin (g/dL) & $5.94 \pm 0.42$ & $5.35 \pm 0.26$ & .01 \\
\hline $\begin{array}{l}\text { Time trauma-ECLS } \\
\quad(\min )\end{array}$ & $351.786 \pm 242.12$ & $385 \pm 103.44$ & .695 \\
\hline $\begin{array}{l}\text { Time active bleeding } \\
\text { (min) }\end{array}$ & $201.4 \pm 90.9$ & $385 \pm 103.4$ & .0032 \\
\hline rfVIIa administration & $64 \%$ & $100 \%$ & .5465 \\
\hline rfVIIa administration & $50 \%$ & $100 \%$ & .278 \\
\hline
\end{tabular}
during ECLS

Data are presented as media \pm standard deviation. The IS is calculated by the following formula: IS $(\mu \mathrm{g} / \mathrm{kg} / \mathrm{min})$ : dosages of dopamine + dobutamine $(\mu \mathrm{g} / \mathrm{kg} /$ $\min )+($ dosages of epinephrine + norepinephrine + isoproterenol $[\mu \mathrm{g} / \mathrm{kg} /$ $\mathrm{min}]) \times 100+$ dosage of milrinone $(\mu \mathrm{g} / \mathrm{kg} / \mathrm{min}) \times 15$. ECLS, Extracorporeal life support; ISS, injury severity score; $C A$, cardiac arrest; $V A$, venoarterial; $V V$, venovenous; $I A B P$, intra-aortic balloon pump; $\mathrm{PaO}_{2}$, arterial oxygen tension; $\mathrm{FIO}_{2}$, inspired oxygen fraction; $\mathrm{PaCO}_{2}$, arterial carbon dioxide tension; $r f \mathrm{VII} a$, recombinant factor VII activated; $I C U$, intensive care unit; $O R$, operating room; $E R$, emergency room.

treatment unsuitability and failure (Table 4). From these significant predictors, by using multivariate regression analysis (Table 5), only ISS greater than 63 (OR, 4.27; CI, 1.37$13.31 ; P=.0407$ ), $\mathrm{pH}$ less than 7.01 (OR, 7.17; CI, 2.48020.752; $P=.0137$ ), and $\mathrm{BL}$ greater than $14.4 \mathrm{mmol} / \mathrm{L}$ (OR, 12.51; CI, 4.47-34.97; $P=.0251$ ) were significantly associated with ECLS failure and individuated as strong predictors of ECLS unsuitability and failure.

\section{Extracorporeal Life Support Treatment Efficacy}

In the ECLS success group, the mean duration of treatment was $128.7 \pm 113$ hours (range, 24-384 hours), with 

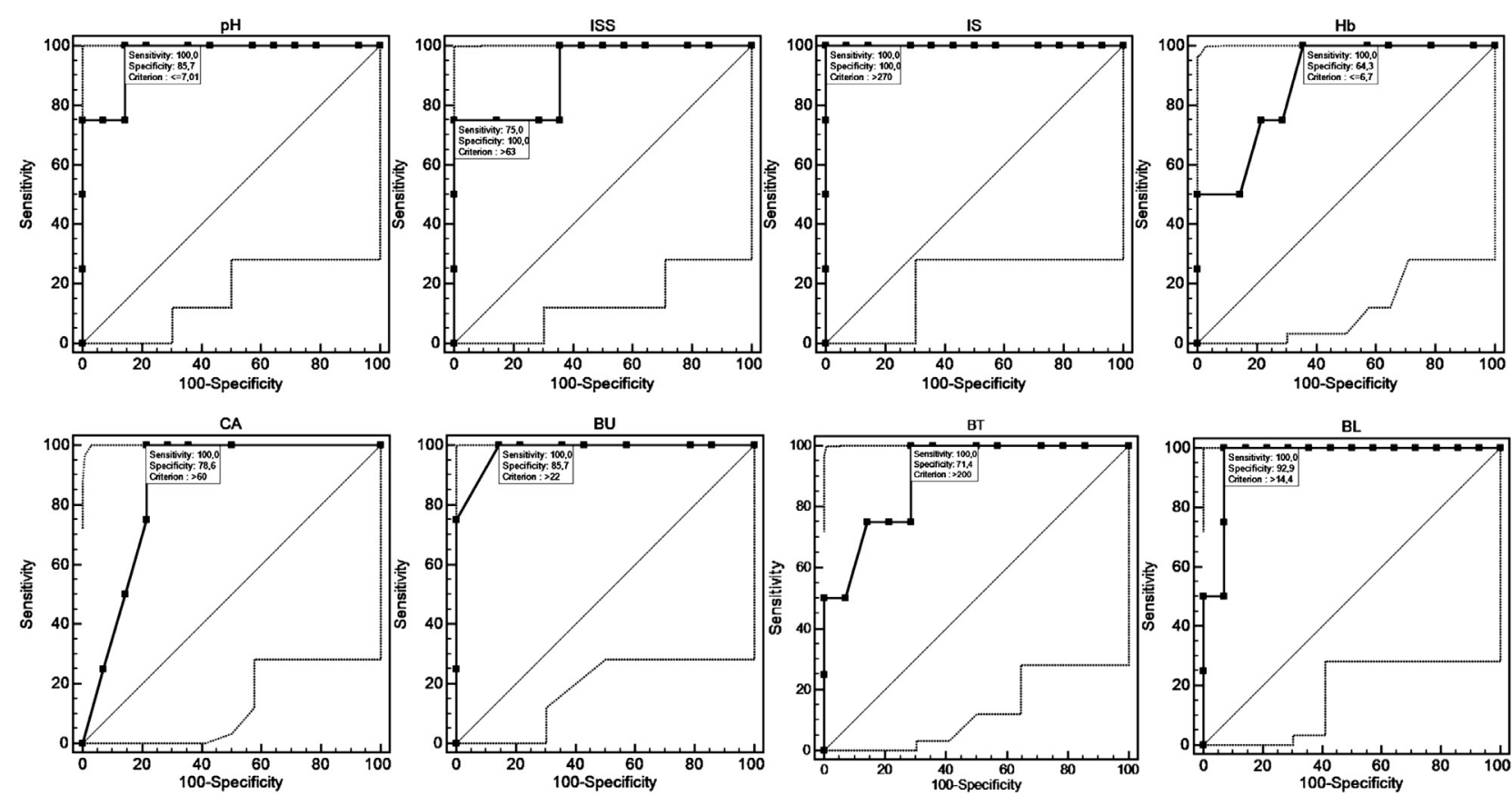

FIGURE 2. Pre-ECLS parameters tested by ROC curves to recognize a cutoff value (criterion) corresponding to the highest Youden index for all significant different parameters between the ECLS failure and success groups. The sensitivity, specificity, and criterion are reported in boxes for all parameters tested. $\mathrm{pH}$ pre-ECLS value is the mean of at least 3 evaluations. $B L$, Blood lactate (the value represents the mean of the last 3 pre-ECLS start evaluations [mmol/L]); $B T$, bleeding time (before ECLS start [min]); $B U$, blood units (infused before ECLS start); $C A$, cardiac arrest (min); $H b$, hemoglobin (the value represents the mean of the last 3 pre-ECLS start evaluations $[\mathrm{g} / \mathrm{dL}]) ; I S$, inotropic score $(\mu \mathrm{g} / \mathrm{kg} / \mathrm{min}) ; I S S$, injury severity score.

significantly longer support time required for VV-ECLS (204 \pm 28 hours), whereas for VA-ECLS, the mean duration was shorter, $98.8 \pm 121.3$ hours $(P=.018)$. During ECLS, damage control surgery was performed in 3 patients, with no bleeding complications.

TABLE 4. Univariate analysis of pre-extracorporeal life support implantation characteristics associated with extracorporeal life support failure (predictors of extracorporeal life support unsuitability)

\begin{tabular}{|c|c|c|c|c|}
\hline Patient data & OR & $\mathbf{9 5} \%$ CI & $Z$ statistic & value \\
\hline ISS $>63$ & 1.8 & $1.193-2.724$ & 2.088 & .037 \\
\hline $\mathrm{CA}>60 \mathrm{~min}$ & 2.96 & $1.258-6.951$ & 2.102 & .035 \\
\hline $\begin{array}{l}\text { Emergency department } \\
\text { application }\end{array}$ & 4.5 & $1.258-6.951$ & 2.316 & .0206 \\
\hline $\begin{array}{c}\mathrm{pH}<7.01 \text { (mean of last } \\
3 \text { evaluations) }\end{array}$ & 1.8 & $1.193-2.715$ & 2.088 & .037 \\
\hline $\begin{array}{l}\text { Lactate }>14.4 \mathrm{mmol} / \mathrm{L} \\
\quad \text { (mean of last } 3 \text { evaluations) }\end{array}$ & 3.9 & $1.860-8.177$ & 2.360 & .0183 \\
\hline IS $>270 \mu \mathrm{g} / \mathrm{kg} / \mathrm{min}$ & 8.1 & $2.775-23.643$ & 2.553 & .0107 \\
\hline Total blood units $>22$ & 7.2 & $1.09-25.019$ & 2.345 & .0221 \\
\hline $\begin{array}{l}\text { Hemoglobin }<6.7 \mathrm{~g} / \mathrm{dL} \\
\quad \text { (mean of last } 3 \text { evaluations) }\end{array}$ & 7.8 & $1.04-5.819$ & 2.276 & .0168 \\
\hline Bleeding time $>200 \mathrm{~min}$ & 6 & $0.97-5.365$ & 2.012 & .0234 \\
\hline
\end{tabular}

$O R$, Odds ratio; $C I$, confidence interval; $I S S$, injury severity score; $C A$, cardiac arrest; $I S$, inotropic score $(\mu \mathrm{g} / \mathrm{kg} / \mathrm{min}=$ dopamine + dobutamine $+15 \times$ milrinone + $100 \times$ epinephrine $+100 \times$ norepinephrine $+100 \times$ isoprotenolol $).$
Arterial blood gas analysis, performed before ECLS and every 2 hours after the deployment, showed significant improvement of $\mathrm{PaO}_{2} /$ inspired oxygen fraction, arterial carbon dioxide tension, and $\mathrm{pH}$, with normalization of all arterial blood gas values at $3.5 \pm 1.5$ hours (range, 2-4 hours) (Figure 3). A comparable trend was registered in mean arterial pressure, which was promptly enhanced by ECLS initiation $(55.68 \pm 12.45$ to $73.45 \pm 9.11$ after $2 \pm 1.2$ hours, $P<.0005)$. IS decreased from $192.1 \pm 50.6$ to $115.68 \pm 48.25(P<.0005)$. A similar trend was recorded for BL concentration: Before ECLS, the mean BL concentration was $7.11 \pm 5.26(2.8-18.2) \mathrm{mmol} / \mathrm{L}$, whereas after

TABLE 5. Multivariate analysis (multivariate logistic regression stepwise model) of significant predictors associated with extracorporeal life support failure revealed by univariate analysis

\begin{tabular}{lccccc}
\hline \multicolumn{1}{c}{ Patient data } & $\begin{array}{c}\text { Regression } \\
\text { coefficient }\end{array}$ & SEM & OR & $\mathbf{9 5 \%}$ CI & $\begin{array}{c}\boldsymbol{P} \\
\text { value }\end{array}$ \\
\hline ISS $>63$ & 1.45273 & 0.1754 & 4.2748 & $1.373-13.314$ & .0407 \\
$\mathrm{pH}<7.01$ (mean of & 1.97044 & 0.1716 & 7.1738 & $2.480-20.752$ & .0137 \\
$\quad \begin{array}{l}\text { last } 3 \text { evaluations) } \\
\text { BL }>14.4 \mathrm{mmol} / \mathrm{L} \\
\quad \text { (mean of last } 3 \\
\quad \text { evaluations) }\end{array}$ & 2.52623 & 0.69933 & 12.5063 & $4.473-34.974$ & .0251 \\
\hline
\end{tabular}

$S E M$, Standard error of mean; $O R$, odds ratio; $C I$, confidence interval; $I S S$, injury severity score; $B L$, blood lactate. 


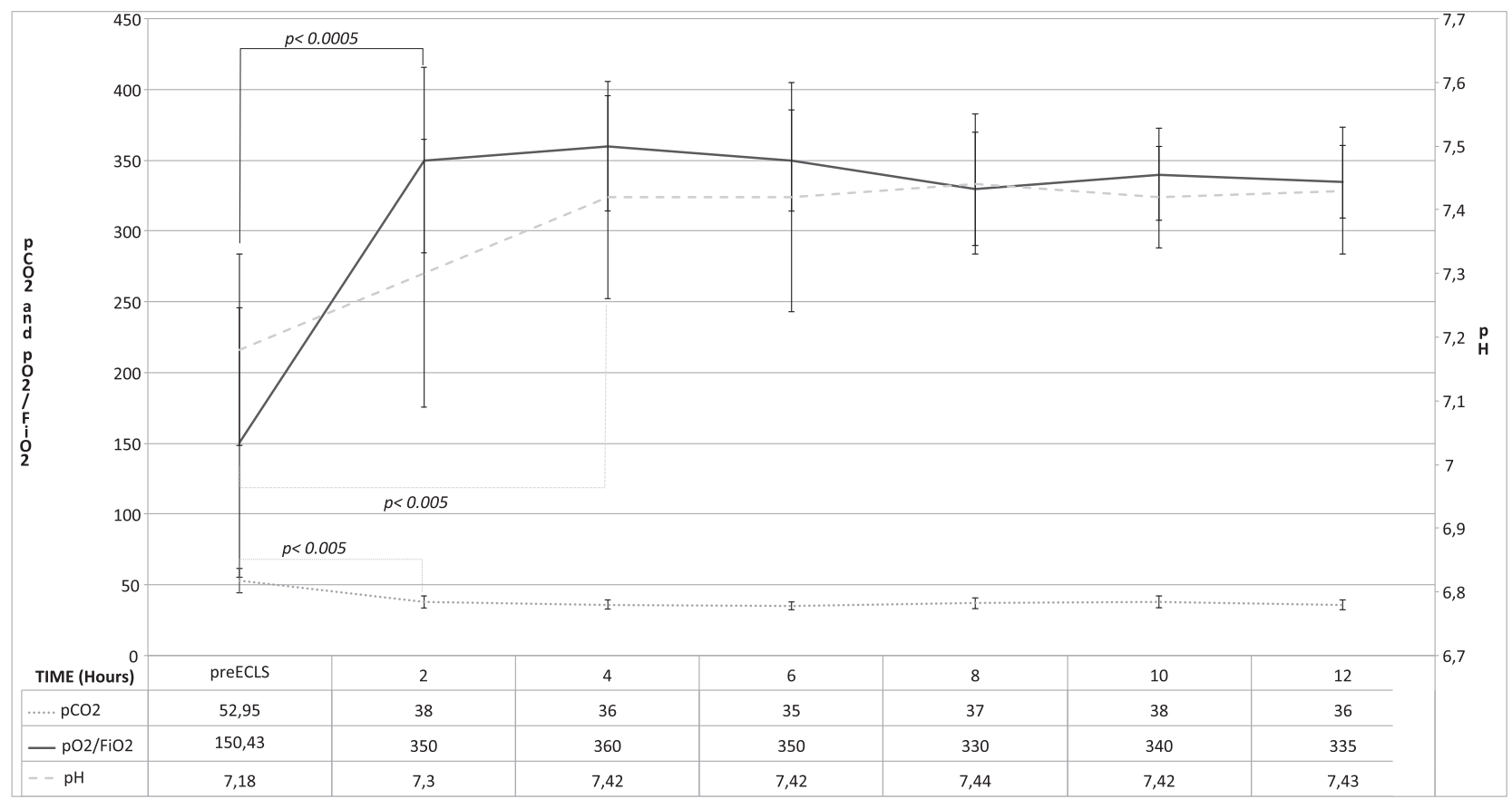

FIGURE 3. ECLS success group. Arterial blood gas analysis parameters are shown from pre-ECLS to 12 hours left. The connection draws (with $P$ value) were between pre-ECLS and the first significantly different value for any parameter. Values are expressed as mean \pm standard deviation. $\mathrm{pH}$ pre-ECLS value is the mean of at least 3 evaluations. $P$ value refers to the first statistically significant variation of each parameter from ECLS start. ECLS, Extracorporeal life support; $\mathrm{PCO}_{2}$, carbon dioxide tension (pre-ECLS value is the mean of at least 3 evaluations [mm $\left.\mathrm{Hg}\right]$ ); $\mathrm{PO}_{2} / \mathrm{FlO}_{2}$, oxygen tension/inspired oxygen fraction (pre-ECLS value is the mean of at least 3 evaluations).

6 hours from ECLS start, there was a significant improvement in this value to $2.16 \pm 1.38(0.5-3.8) \mathrm{mmol} / \mathrm{L}$ $(P=.004)$ (Figure 4).

An intra-aortic balloon pump (used only in VA-ECLS) was inserted in 2 patients (14.3\% of VA-ECLS). In case of sepsis or ongoing renal and hepatic failure, additional support was given to the patient by using the continuous VV hemofiltration device $(\mathrm{n}=7,50 \%)$, plasmapheresis, the detoxification device $(\mathrm{n}=2,14.3 \%)$, and endotoxin removal cartridge $(\mathrm{n}=3,21.4 \%)$. Renal replacement therapy was successfully performed, allowing the kidneys to recover. Hepatic failure was effectively treated by removing large lipophilic molecules from plasma. In case of septic shock, maximal treatment was ensured by integrating an endotoxin removal cartridge in the circuit. In 7 patients $(50 \%)$ in the ECLS success group with extensive craniocerebral trauma, ECLS was used to allow time for brain death assessment and was continued to support organ donation, which was possible in all cases (100\% effectiveness). One patient did not complete the organ donation procedure because of the relatives' opposition. The liver from all other patients $(\mathrm{n}=6)$ and 3 kidneys were donated.

Among the 7 remaining patients $(50 \%$ of ECLS success group), $2(28.6 \%)$ died of septic multiple organ failure (at days 7 and 16 of treatment) during ECLS, and 5 (71.4\%) survived to discharge. All survivors were discharged from the intensive care unit to hospital wards and followed the necessary rehabilitative programs available. After rehabilitation, all the survivors returned home; only 1 patient $(20 \%)$ was in cerebral performance category 2 , and the remaining patients $(\mathrm{n}=4,80 \%)$ were in category 1 and able to manage their own affairs before the index event.

ECLS-related complications were observed in 2 patients: $1 \mathrm{leg}$ ischemia due to femoral artery cannulation and $1 \mathrm{ox}-$ ygenator failure due to clot formation (after 13 days of use). The first complication was promptly solved by moving vascular access to the axillary artery, and the second complication was detected early enough because of continuous monitoring and was corrected with the substitution of the membrane lung. The results and complications in the ECLS success group are shown in Table 6.

\section{DISCUSSION}

Since the first pioneering experience of ECLS used in a patient with trauma in $1971,{ }^{12}$ many advances in technology, materials, and intensive care have occurred. ${ }^{10,11}$ The use of ECLS in cardiogenic shock and pulmonary failure of different causes has been accepted, and a new group of indications is being considered.

Severe trauma is a serious matter not only because it causes disablement and numerous deaths but also because the social cost is even more dramatic, with regard to the large number of young people involved. ${ }^{1}$ Moreover, mortality rates due to major trauma are still high, despite 


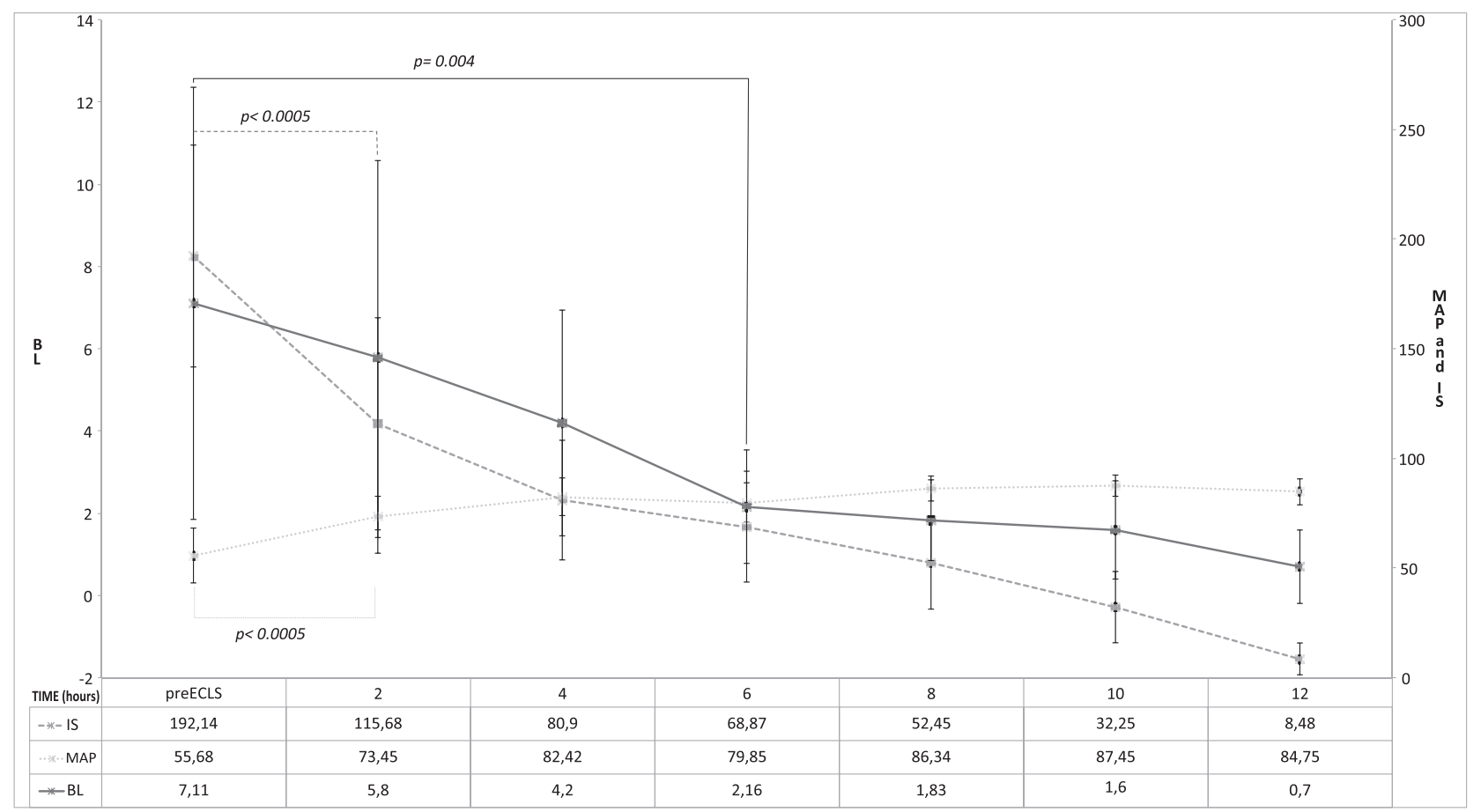

FIGURE 4. ECLS success group. Hemodynamic parameters are shown from pre-ECLS to 12 hours left. The connection draws (with $P$ value) were between pre-ECLS and the first significant different value for any parameter. Values are expressed as mean \pm standard deviation. $P$ value refers to the first statistically significant variation of each parameter from ECLS start. BL, Blood lactate (pre-ECLS value is the mean of at least 3 evaluations [mmol/L]); ECLS, extracorporeal life support (pre-ECLS value is the mean of at least 3 evaluations); IS, inotropic score (pre-ECLS value is the mean of at least 3 evaluations $[\mu \mathrm{g} / \mathrm{kg} / \mathrm{min}]) ; M A P$, mean arterial pressure (pre-ECLS value is the mean of at least 3 evaluations [mm $\mathrm{Hg}]$ ).

advanced treatments. The first experiences of ECLS in trauma care have been reported, ${ }^{5,14}$ with encouraging outcomes, suggesting that ECLS seems to be a valid option in patients with severe trauma and refractory cardiopulmonary failure, preventing potentially evolving shock and maintaining tissue perfusion, oxygenation, and organ function.

Actual ECLS devices are small and portable; suitable for both intra- and inter-hospital transport; and easy, fast, and safe to implant, even in an out-of-hospital scenario. ${ }^{25}$ In the current study and the study by Arlt and colleagues, ${ }^{5}$ anticoagulation can be safely delayed for 48 or 72 hours because of improved biocompatibility. Anticoagulation can be maintained on mild levels, reducing bleeding complications during ECLS, which is the first problem in this setting and mainly accepted as a major contraindication to the treatment. In adjunct, the current study and the study by Steinbrueckner and colleagues ${ }^{26}$ found that blood cell consumption is decreased by actual centrifugal pumps, significantly reducing the need for blood transfusions and their related complications. All of these important advantages have made ECLS a safe and feasible technique, which has been demonstrated in many conditions. ${ }^{9-11}$ In patients with polytrauma, severe coagulopathies and preexisting bleeding remain mostly accepted as contraindications to ECLS, and no definitive proof of its safety, feasibility, and effectiveness in polytrauma cases has been reported.

Our study presents a specific category of patients with polytrauma with extremely severe clinical conditions and refractory cardiopulmonary failure. The study patients were supported by a high level of inotropes or intra-aortic balloon pump and ventilator maximal support, and the majority of these patients $(61.1 \%)$ received ECLS with prolonged continuous cardiac massage. In all patients, the preECLS blood gas analysis data were poor $\left(\mathrm{pH}, \mathrm{PaO}_{2}\right.$, arterial carbon dioxide tension, BL). The mortality predicted from the ISS score (mean, $53 \pm 17$ ) and prolonged cardiopulmonary resuscitation was greater than $90 \%$. Thus, it is clear that the application of ECLS in these patients in critical condition, as evidenced by the results of our study, can reduce mortality to a more acceptable $64.3 \%$ (9 deaths in 14 patients, considering the ECLS success group), with an important possibility of organ recovery for donation.

After supporting vital function by ECLS, the first goal in the treatment of these patients remains the restoration of blood coagulation. As did Arlt and colleagues, ${ }^{5}$ we initially started heparin-free ECLS support $(16.7 \pm 19$ hours after initiation). The treatment of hemorrhagic status and coagulation disorders was carried out according to the recommendations for blood component transfusion in patients with trauma. ${ }^{3}$ When clinical and hemocoagulation laboratory 
TABLE 6. Extracorporeal life support success group: Modalities, results, complications, and outcome

\begin{tabular}{|c|c|}
\hline Patient characteristics & $\begin{array}{l}\text { Value (mean } \pm \text { SD; } \\
\text { max-min) }\end{array}$ \\
\hline \multicolumn{2}{|l|}{ ECLS modality } \\
\hline VV-ECLS & $2(14.3 \%)$ \\
\hline VA-ECLS & $12(85.7 \%)$ \\
\hline On ECLS time (h) & $128.7 \pm 113(24-384)$ \\
\hline VV-ECLS time (h) & $204 \pm 28(165-231)$ \\
\hline VA-ECLS time $(\mathrm{h})$ & $98.8 \pm 121.3(24-384)$ \\
\hline Damage-control surgery & $3(21.4 \%)$ \\
\hline IABP & $2(14.3 \%)$ \\
\hline \multicolumn{2}{|l|}{ Adjunctive treatment modules } \\
\hline $\mathrm{CVVH}$ & $7(50 \%)$ \\
\hline Endotoxin removal cartridge & $3(21.4 \%)$ \\
\hline Hepatic & $2(14.3 \%)$ \\
\hline \multicolumn{2}{|l|}{ Complications } \\
\hline Leg ischemia & $1(7.1 \%)$ \\
\hline Oxygenator failure & $1(7.1 \%)$ \\
\hline \multicolumn{2}{|l|}{ Outcome } \\
\hline Cerebral death and organ donation & $7(50 \%)$ \\
\hline Death due to septic multiple organ failure & $2(28.6 \%)$ \\
\hline Survival & $5(71.4 \%)$ \\
\hline \multicolumn{2}{|l|}{$\begin{array}{l}\text { Survivors' }(\mathrm{n}=5 \text { ) cerebral performance } \\
\text { category (after rehabilitation) }\end{array}$} \\
\hline Category 4 & $0(0 \%)$ \\
\hline Category 3 & $0(0 \%)$ \\
\hline Category 2 & $1(20 \%)$ \\
\hline Category 1 & $4(80 \%)$ \\
\hline
\end{tabular}

data were normalized, heparin administration was started to maintain an activated partial thromboplastin time range equal to 50 to 60 seconds. During the phase of hemostatic function treatment, patients were maintained in a normothermic state by the ECLS system to avoid the negative hemocoagulative effects of hypothermia. ${ }^{3,4}$ Moreover, blood acidosis (and its negative effects on coagulation system) could be corrected by ECLS.

In VV configuration as respiratory support, ECLS allows a more protective ventilation strategy, reducing ventilatorinduced lung injury and allowing time for lung rest and recovery. Patients with thoracic trauma and pulmonary contusions resulting in post-traumatic acute respiratory distress syndrome, in which ventilation management is challenging, can be safely sustained by ECLS for days, until pulmonary function is restored and weaning is possible.

As cardiopulmonary support in the VA setting, ECLS is effective in maintaining hemodynamic stability and systemic perfusion when fluid resuscitation and inotropic infusion are insufficient. Management of bleeding sites is necessary to reach stable hemostasis; thus, adequate blood flow in the circuit is provided and ECLS procedure is effective. Institution of ECLS in emergency situations (eg, during CA) is possible and produces good outcomes. In the current study, ECLS was started during resuscitation maneuvers in 6 patients, 2 of whom were successfully supported allowing the goal to be achieved (1 survival and 1 organ donation). The reported parameters and statistical analysis strengthen these results, confirming that ECLS is effective in rapidly improving respiratory and hemodynamic function, as reported by Arlt and colleagues ${ }^{5}$ and Huang and colleagues. ${ }^{14}$

ECLS proved to be effective in expanding the donor pool and allowing time for brain death assessment, when hemodynamic instability threatens to interrupt it. However, the clinical limitations and suitability of ECLS treatment are yet to be observed in this category of patients. ${ }^{5,14}$ Currently, there is no identified, reported predictor of ECLS success based on the patient's clinical status before implantation. The identification of predictors for ECLS unsuitability and failure could result in better identification of patients with a greater efficacy and better allocation of resources and cost-effectiveness.

By focusing on an analysis of ECLS success, we tried to evaluate the preimplant parameters in those patients in whom injuries were too severe for ECLS and ECLS was not appropriate. We considered all of the accessible clinical, instrumental, and laboratory parameters in an emergency setting that did not require an invasive procedure or timeconsuming measurements. The data can be evaluated within minutes after a patient's admittance to the emergency department. To make the evaluation as simple and fast as possible, all continuous variables were dichotomized by ROC curves for estimation of cutoff values with the best sensibility and specificity. From our data, the univariate and multivariate statistical analyses showed that the following parameters had the highest negative impact: BL greater than $14.4 \mathrm{mmol} / \mathrm{L}, \mathrm{pH}$ less than 7.01 among laboratory values, and ISS greater than 63 among clinical data. No ultrasonography or hemodynamic parameter contributed significantly to the prediction of ECLS success or failure. CA was relatively significant as a predictor (on univariate analysis but not on multivariate analysis) only if it lasted more than 60 minutes.

These results seem to suggest that ECLS should be avoided when tissue perfusion is strongly impaired for an extended time; when the patient is in severe shock status for a long time, ECLS treatment is probably not indicated. The patient most likely has entered the irreversible stage of shock, dominated by disseminated intravascular coagulation and severely altered permeability of the microcirculation. ${ }^{27}$ This irreversible stage of shock is clinically characterized by a severe and irreversible hemorrhagic status, and is therefore uncontrollable and uncontainable (even with advanced therapeutic solutions, eg, coagulation factors and activated factor VII). In our experience, it is impossible in this advanced stage of shock, even with ECLS, 
to interrupt the vicious cycle of hemorrhagic shock, blood acidosis, coagulopathy, and inadequate tissue perfusion and oxygen supply. ECLS always was considered as the last option and was deployed in those patients in whom maximal advanced therapies had been exhausted with no improvement. When the ECLS team decided to begin ECLS, there was collegial conviction that no other treatment option was available and that awaited mortality was $100 \%$. Even in this clinical setting, observed mortality was $64.3 \%$ (9 deaths in 14 patients), which was lower than we expected.

\section{Study Limitations}

Several limitations are important to note in the current study. First, the number of enrolled patients was not large enough to yield completely persuasive and conclusive results. Second, different clinical scenarios were present in the polytraumatized patients, and the evaluation may be nonhomogeneous. Third, some selection bias for the treatment may exist. The emergency department doctor was the first decision-maker for ECLS team activation; therefore, it may be assumed that the patients' conditions were difficult to manage.

\section{CONCLUSIONS}

ECLS is a safe and feasible technique. ECLS has proved to be lifesaving in multiply injured patients with refractory cardiopulmonary failure when it is promptly initiated in a specialized center. Advanced management of patients with polytrauma should include ECLS in case of refractoriness of the clinical conditions to conventional treatments and if no predictor of ECLS failure is present. Our data allowed the identification of strong predictors of ECLS nonsuitability and success in polytraumatized patients, which may be helpful in deciding whether an ECLS device should be implanted in severely complex and compromised cases. Because ECLS does not impede conventional therapies, it should be instituted early alongside them, not only to give the patient the maximal chance of survival but also as a new way of expanding the donor pool for organ transplantation. Future improvements in materials and techniques are expected to make ECLS even easier and safer to manage, leading to a further extension of its use in severely injured patients.

\section{References}

1. Krug EG, Sharma GK, Lozano R. The global burden of injuries. Am J Public Health. 2000;90:523-6.

2. Probst C, Zelle BA, Sittaro NA, Lohse R, Krettek C, Pape HC. Late death after multiple severe trauma: when does it occur and what are the causes? J Trauma. 2009;66:1212-7.

3. Spahn DR, Rossaint R. Coagulopathy and blood component transfusion in trauma. Br J Anaesth. 2005;95:130-9.
4. Drummond JC, Petrovitch CT. The massively bleeding patient. Anesthesiol Clin North Am. 2001;19:633-49.

5. Arlt M, Philipp A, Voelkel S, Rupprecht L, Mueller T, Hilker M, et al. Extracorporeal membrane oxygenation in severe trauma patients with bleeding shock. $R e$ suscitation. 2010;81:804-9.

6. Hemmila MR, Napolitano LM. Severe respiratory failure: advanced treatment options. Crit Care Med. 2006;34:S278-90.

7. Rico FR, Cheng JD, Gestring ML, Piotrowski ES. Mechanical ventilation strategies in massive chest trauma. Crit Care Clin. 2007;23:299-315.

8. Cohn SM. Pulmonary contusion: review of the clinical entity. J Trauma. 1997;42: 973-9.

9. Beckmann A, Benk C, Beyersdorf F, Haimerl G, Merkle F, Mestres C, et al, ECLS Working Group. Position article for the use of extracorporeal life support in adult patients. Eur J Cardiothorac Surg. 2011;40:676-80.

10. Bartlett RH, Gattinoni L. Current status of extracorporeal life support (ECMO) for cardiopulmonary failure. Minerva Anestesiol. 2010;76:534-40.

11. Tiruvoipati R, Botha J, Peek G. Effectiveness of extracorporeal membrane oxygenation when conventional ventilation fails: valuable option or vague remedy? $J$ Crit Care. 2012;27:192-8

12. Hill JD, O'Brien TG, Murray JJ, Dontigny L, Bramson ML, Osborn JJ, et al. Prolonged extracorporeal oxygenation for acute post-traumatic respiratory failure (shock-lung syndrome). Use of the Bramson membrane lung. N Engl J Med. 1972;286:629-34.

13. Larsson M, Talving P, Palmér K, Frenckner B, Riddez L, Broomé M. Experimental extracorporeal membrane oxygenation reduces central venous pressure: an adjunct to control of venous hemorrhage? Perfusion. 2010;25:217-23.

14. Huang YK, Liu KS, Lu MS, Wu MY, Tsai FC, Lin PJ. Extracorporeal life support in post-traumatic respiratory distress patients. Resuscitation. 2009;80:535-9.

15. Cordell-Smith JA, Roberts N, Peek GJ, Firmin RK. Traumatic lung injury treated by extracorporeal membrane oxygenation (ECMO). Injury. 2006;37:29-32.

16. Magliocca JF, Magee JC, Rowe SA, Gravel MT, Chenault RH 2nd, Merion RM, et al. Extracorporeal support for organ donation after cardiac death effectively expands the donor pool. J Trauma. 2005;58:1095-101.

17. Hsieh CE, Lin HC, Tsui YC, Lin PY, Lin KH, Chang YY, et al. Extracorporeal membrane oxygenation support in potential organ donors for brain death determination. Transplant Proc. 2011;43:2495-8.

18. Ciapetti M, Cianchi G, Zagli G, Greco C, Pasquini A, Spina R, et al. Feasibility of inter-hospital transportation using extra-corporeal membrane oxygenation (ECMO) support of patients affected by severe swine-flu (H1N1)-related ARDS. Scand J Trauma Resusc Emerg Med. 2011;19:32.

19. Bonacchi M, Harmelin G, Peris A, Sani G. A novel strategy to improve systemic oxygenation in venovenous extracorporeal membrane oxygenation: the " $\chi$-configuration" J Thorac Cardiovasc Surg. 2011;142:1197-204.

20. Niebler RA, Punzalan NC, Marchan M, Lankiewicz MW. Activated recombinant factor VII for refractory bleeding during extracorporeal membrane oxygenation. Pediatr Crit Care Med. 2010;11:98-102.

21. Polderman KH. Hypothermia and neurological outcome after cardiac arrest: state of the art. Eur J Anaesthesiol Suppl. 2008;42:23-30.

22. Peris A, Tutino L, Zagli G, Batacchi S, Cianchi G, Spina R, et al. The use of point-of-care bedside lung ultrasound significantly reduces the number of radiographs and computed tomography scans in critically ill patients. Anesth Analg. 2010;111:687-92

23. Cruz DN, Antonelli M, Fumagalli R, Foltran F, Brienza N, Donati A, et al. Early use of polymyxin B hemoperfusion in abdominal septic shock: the EUPHAS randomized controlled trial. JAMA. 2009;301:2445-52.

24. Shore S, Nelson DP, Pearl JM, Manning PB, Wong H, Shanley TP, et al. Usefulness of corticosteroid therapy in decreasing epinephrine requirements in critically ill infants with congenital heart disease. Am J Cardiol. 2001;88:591-4.

25. Lebreton G, Pozzi M, Luyt CE, Chastre J, Carli P, Pavie A, et al. Out-of-hospital extra-corporeal life support implantation during refractory cardiac arrest in a half-marathon runner. Resuscitation. 2011;82:1239-42.

26. Steinbrueckner BE, Steigerwald U, Keller F, Neukam K, Elert O, Babin-Ebell J. Centrifugal and roller pumps-are there differences in coagulation and fibrinolysis during and after cardiopulmonary bypass? Heart Vessels. 1995;10:46-53.

27. Gando S, Sawamura A, Hayakawa M. Trauma, shock, and disseminated intravascular coagulation: lessons from the classical literature. Ann Surg. 2011; 254:10-9. 